\title{
Nogo Receptor Antagonism Promotes Stroke Recovery by Enhancing Axonal Plasticity
}

\author{
Jung-Kil Lee, Ji-Eun Kim, Michael Sivula, and Stephen M. Strittmatter \\ Department of Neurology, Yale University School of Medicine, New Haven, Connecticut 06510
}

\begin{abstract}
After ischemic stroke, partial recovery of function frequently occurs and may depend on the plasticity of axonal connections. Here, we examine whether blockade of the Nogo-NogoReceptor (NgR) pathway might enhance axonal sprouting and thereby recovery after focal brain infarction. Mutant mice lacking NgR or Nogo- $\mathrm{AB}$ recover complex motor function after stroke more completely than do control animals. After a stroke, greater numbers of axons emanating from the undamaged cortex cross the midline to innervate the contralateral red nucleus and the ipsilateral cervical spinal cord; this axonal plasticity is enhanced in $n g r-/-$ or nogo-ab $-/-$ mice. In rats with middle cerebral artery occlusion, both the recovery of motor skills and corticofugal axonal plasticity are promoted by intracerebroventricular administration of a function-blocking NgR fragment. Behavioral improvement occurs when therapy is initiated 1 week after arterial occlusion. Thus, delayed pharmacological blockade of the NgR promotes subacute stroke recovery by facilitating axonal plasticity.
\end{abstract}

Key words: stroke; axon; Nogo; Nogo-66 receptor; red nucleus; corticofugal

\section{Introduction}

Recovery from ischemic stroke is quite variable but typically follows a time course in which most improvement occurs over 1-6 months (Wade and Hewer, 1987; Bonita and Beaglehole, 1988; Reding and Potes, 1988). To the extent that recovery occurs, function appears to be redistributed to parallel pathways or to new alternate pathways, or both. For example, partial recovery from the contralateral hemiparesis associated with a stroke involving the primary motor cortex sometimes involves activation of regions in the opposite, undamaged hemisphere (Pineiro et al., 2001; Feydy et al., 2002; Schaechter et al., 2002; Small et al., 2002; Foltys et al., 2003; Fujii and Nakada, 2003; Zemke et al., 2003). In other cases, activation of regions ipsilateral to the stroke occurs as new neurons are recruited to perform specific tasks (Pineiro et al., 2001; Feydy et al., 2002; Small et al., 2002; Foltys et al., 2003; Fujii and Nakada, 2003; Werhahn et al., 2003; Zemke et al., 2003). Similar shifts have been demonstrated during recovery in rodent models (Dijkhuizen et al., 2001). It is likely that both anatomical changes in the pattern of existing connectivity and altered electrical patterns in stable connections account for these shifts in activation patterns during specific tasks. There is some evidence that plasticity and recovery after stroke can be enhanced in the subacute phase by focused training regimens (van der Lee et al., 1999; Bland et al., 2001; Liepert et al., 2001; Wolf et al., 2002) or by increased monoaminergic activation with $\mathrm{D}$-amphetamine (Hurwitz et al., 1991; Walker-Batson et al., 1995; Stroemer et al.,

Received April 29, 2004; revised May 20, 2004; accepted May 26, 2004.

This work was supported by grants from the National Institutes of Health to S.M.S. We thank Yiguang Fu and Stefano Sodi for excellent technical assistance and Biogeldec for providing the $\mathrm{NgR}(310)$ Ecto-Fc protein.

Correspondence should be addressed to Stephen M. Strittmatter, Department of Neurology, Yale University, P.0. Box 208018, New Haven, CT 06510. E-mail: stephen.strittmatter@yale.edu.

DOI:10.1523/JNEUROSCI.1643-04.2004

Copyright $\odot 2004$ Society for Neuroscience $\quad$ 0270-6474/04/246209-09\$15.00/0
1998; Knecht et al., 2001; Sonde et al., 2001; Walker-Batson et al., 2001). Inosine and FGF treatments have also been reported to increase axonal plasticity and functional recovery from stroke in rodents (Kawamata et al., 1997; Chen et al., 2002); however, there is currently no clinically useful pharmacological method to enhance stroke recovery.

In recent years, some molecular determinants of axonal regeneration and plasticity in the adult brain have been defined (McGee and Strittmatter, 2003). CNS myelin is a primary inhibitor of axonal growth in the adult brain, and three proteins, Nogo-A (Chen et al., 2000; GrandPre et al., 2000; Prinjha et al., 2000), myelin-associated glycoprotein (MAG) (McKerracher et al., 1994; Mukhopadhyay et al., 1994), and oligodendrocyte myelin glycoprotein (OMgp) (Wang et al., 2002), appear to be responsible for this inhibition of axonal growth. A receptor molecule, Nogo-66 Receptor (NgR), mediates the action of one of two Nogo-A inhibitory domains (Fournier et al., 2001), as well as the action of MAG (Domeniconi et al., 2002; Liu et al., 2002) and OMgp (Wang et al., 2002) on axons. These pathways have been studied most intensively in traumatic spinal cord injury. Suppression of myelin inhibition of axonal growth by myelin immunization promotes axonal growth and regeneration (Huang et al., 1999). Similar results have been obtained with anti-Nogo-A antibodies (Schnell and Schwab, 1990; Bregman et al., 1995; Brosamle et al., 2000) and with a peptide antagonist of Nogo-66 binding to the NgR (GrandPre et al., 2002; Li and Strittmatter, 2003). These reagents are selective blockers of Nogo function and do not disrupt MAG or OMgp function. We have shown that a soluble ectodomain fragment of the NgR blocks myelin inhibition of axon growth more effectively in vitro (Fournier et al., 2002). The IgG fusion protein, $\mathrm{NgR}(310)$ Ecto- $\mathrm{Fc}$, is also more effective than Nogo extracellular peptide 1-40 (NEP1-40) in promoting axonal growth and recovery after spinal cord injury (SCI) 
(our unpublished observations). Genetic studies of the role of these inhibitors have been less informative. CNS axon growth is not promoted in MAG knock-out animals (Bartsch et al., 1995), nor is it observed in one line of Nogo-A/B knock-out animals (Zheng et al., 2003). In two other lines of Nogo-AB knock-out mice there is partial penetrance of an enhanced axonal regeneration phenotype (Kim et al., 2003; Simonen et al., 2003). Mice lacking NgR exhibit improved recovery of locomotor function after spinal injury, with regenerative growth in some axonal tracts but not others (our unpublished observations).

In this study we sought to determine whether reduction in the activity of the Nogo-NgR pathway might allow increased axonal sprouting after stroke and thereby promote behavioral recovery. There have been previous reports of some benefit from antiNogo antibody treatment of rats with middle cerebral artery occlusion (MCAO) (Papadopoulos et al., 2002; Wiessner et al., 2003). No genetic analysis of the Nogo-NgR system has been made in stroke. Furthermore, the previously studied antibodies target a second inhibitory domain in Nogo-A and do not directly block Nogo-66-NgR function (Fournier et al., 2001). In the current study we used both genetic and pharmacologic methods to assess the role of the Nogo-NgR system in limiting axonal plasticity and behavioral recovery after ischemic stroke. We find that reduction of Nogo-NgR function enhances axonal sprouting from the uninjured cerebral cortex and improves the return of motor task performance.

\section{Materials and Methods}

Gene-targeted mouse strains. The nogo-ab - / gene trap line has been described previously (Kim et al., 2003). The generation and characterization of $n g r-/-$ mice have been described previously (our unpublished observations). The mutation in these mice deletes exon II of the ngr gene, which encodes the entire mature NgR protein. No $n g r$ mRNA or NgR protein is detectable in these mice. In this study, all mice had been backcrossed to C57BL6 mice for at least five generations, and littermate heterozygous mice were used as controls in all experiments.

Photothrombotic cortical lesion and fiber tracing in mice. All surgical procedures and postoperative care was performed in accordance with guidelines of the Yale Animal Care and Use Committee. Focal cortical ischemia was induced in male mice ( $8-10$ weeks old) weighing $20-25 \mathrm{gm}$ by photothrombosis of cortical microvessels as described previously in detail (Boquillon et al., 1992; Schroeter et al., 2002). Each mouse was anesthetized with $2 \%$ isoflurane and maintained with $1 \%$ isoflurane in an oxygen/air mixture using a gas anesthesia mask in a stereotaxic frame (Stoelting, Wood Dale, IL). The rectal temperature was controlled during surgery at $37 \pm 0.5^{\circ} \mathrm{C}$ with a homeothermic blanket (Harvard Apparatus, Holliston, MA). Rose Bengal (Sigma, St. Louis, MO), $0.1 \mathrm{ml}$ of a 10 $\mathrm{mg} / \mathrm{ml}$ solution in normal saline, was infused intraperitoneally via a 1 $\mathrm{mm}$ peritoneal incision $5 \mathrm{~min}$ before illumination. The skull was exposed via a midline incision of the skin. For illumination, a fiber optic bundle of a cold light source (KL1500 LCD, Zeiss, Oberkochen, Germany) with a $4.5 \mathrm{~mm}$ aperture was centered $2.4 \mathrm{~mm}$ to the left of bregma. The brain was illuminated for $15 \mathrm{~min}$ through the exposed intact skull. The scalp was sutured, and mice were allowed to awaken. Two weeks after surgery, a burr hole was made in the skull overlying the right sensorimotor cortex to trace the corticospinal tract after induction of anesthesia with intraperitoneal ketamine $(100 \mathrm{mg} / \mathrm{kg})$ and xylazine $(15 \mathrm{mg} / \mathrm{kg})$. Biotin dextran amine (BDA) (MW 10,000; 10\% in PBS; Molecular Probes, Eugene, OR) was applied with three injections at a depth of $0.5 \mathrm{~mm}$ from the cortical surface (Kim et al., 2003; Li and Strittmatter, 2003).

Permanent middle cerebral artery occlusion in rats. Adult male Sprague Dawley rats (Charles River Laboratories, Wilmington, MA) weighing 250-350 gm were used. Left middle cerebral artery occlusion was induced with a intraluminal filament (Longa et al., 1989; Belayev et al., 1996; Hudzik et al., 2000). Anesthesia was induced with 5\% isoflurane and maintained with $2 \%$ isoflurane in an oxygen/air mixture using Fluo- vac Scavenger (Stoelting). The rectal temperature was maintained at $37 \pm 0.5^{\circ} \mathrm{C}$ with a homeothermic blanket (Harvard Apparatus). Under an operating microscope, the left common carotid artery (CCA) was exposed through a midline neck incision and dissected from its bifurcation to the base of the skull. After coagulation of the occipital artery branches of the external carotid artery (ECA), the left ECA was coagulated along with the terminal lingual and maxillary artery branches, which were then divided. The left internal carotid artery (ICA) was isolated, and the pterygopalatine artery was ligated close to its origin with a silk suture. A microaneurysm clip was placed across both the CCA and the ICA to prevent bleeding during the insertion of the suture. After the silk suture was tied loosely around the mobilized ECA stump, a small incision was made on the ECA stump, and a $23 \mathrm{~mm}$ length of 4- 0 monofilament nylon suture, heat-blunted at the tip and coated with poly-Llysine, was inserted into the lumen of the ICA. The temporary clip on the ICA was removed, and the nylon suture was advanced $18-20 \mathrm{~mm}$ from the bifurcation of the CCA until mild resistance was felt. The silk suture around the ECA stump was tightened on the intraluminal nylon suture. After removal of the microaneurysm clip, the neck incision was closed. Rats that failed to exhibit neurological abnormalities at $24 \mathrm{hr}$ after stroke were excluded from further study.

Drug administration and axonal tracing in rat. An osmotic minipump (Alzet 2ML4, Alza Scientific Products, Palo Alto, CA) was implanted 1 week after cerebral ischemia. The pump, which was designed to deliver $2.5 \mu \mathrm{l} / \mathrm{hr}$ for $28 \mathrm{~d}$, was filled with $2 \mathrm{ml}$ of a $1.2 \mathrm{mg} / \mathrm{ml}$ solution of $\mathrm{NgR}(310)$ Ecto-Fc or Rat IgG in PBS. For pump implantation, all animals were anesthetized with isoflurane and oxygen using a gas anesthesia mask for the stereotaxic instrument (Stoelting) and placed in a stereotaxic frame. After the scalp was reopened, a pocket was formed over the neck and scapulas to hold the minipump. A burr hole was drilled in the skull, and the cannula (Alzet brain infusion kit II, Alza Scientific Products) was introduced into the right lateral ventricle at stereotaxic coordinates 0.6 $\mathrm{mm}$ posterior and $1.2 \mathrm{~mm}$ lateral to bregma and $4.0 \mathrm{~mm}$ deep to the pial surface. The cannula was held in place with cyanoacrylate, and the skin was sutured (Nakamura et al., 2001; Harrigan et al., 2002). Pumps were replaced after $28 \mathrm{~d}$ and connected to the same cannula. To trace corticofugal axons, a burr hole was made in the skull overlying the right sensorimotor cortex after removal of the minipump and cannula at 9 weeks after MCAO. BDA (MW 10,000; 10\% in PBS; Molecular Probes) was applied at seven injection sites at a depth of $1.5 \mathrm{~mm}$ from the cortical surface (GrandPre et al., 2002).

Behavioral testing. All animals were housed in individual cages. Before induction of ischemia, all animals received training in the staircase and rotarod test, and animals not achieving criteria were excluded from further study. The rotarod test was used to examine balance and coordination in both rats and mice (Hunter et al., 2000; Li and Stephenson, 2002). Rats were trained on the rotarod on 5 consecutive days for a total of 15 sessions before surgery, and mice were trained for 3 consecutive days and a total 9 sessions. The rotating drum was accelerated from 4 to $40 \mathrm{rpm}$ over $5 \mathrm{~min}$, and the latency in seconds for the animal to fall off the drum was recorded. Each session included three consecutive trials, with a maximum time of $300 \mathrm{sec}$, and the mean fall latency was calculated from the three trials. Animals that did not stay on the rod for an average of at least $1 \mathrm{~min}$ at the end of training were excluded from the stroke surgery.

The staircase test was used to test skilled forepaw use (Montoya et al., 1991; Virley et al., 2000; Baird et al., 2001). Food was restricted during the pre-stroke training period and $5 \mathrm{~d}$ after surgery to provide motivation for food rewards. All animals were food restricted to $85-90 \%$ of their freefeeding weight. Animals were returned to a free feeding schedule for $5 \mathrm{~d}$ after surgery to improve postoperative weight and recovery. All animals were fed standard laboratory chow at the end of each test: $12-15 \mathrm{gm}$ for rats and 3-4 gm for mice. Animals were placed in the staircase apparatus (Lafayette Instrument, Lafayette, IN). Each step of the stairs was baited with two food pellets of $45 \mathrm{mg}$ of chocolate-flavored purified pellet for rats and $14 \mathrm{mg}$ of purified pellet for mice (Bioserve, Frenchtown, NJ). Seven steps for rats or eight steps for mice were baited. Each test session lasted $15 \mathrm{~min}$ for rats and $30 \mathrm{~min}$ for mice. The number of pellets retrieved and eaten per side was used as a measure of forelimb reaching ability. Animals were trained for 2 weeks before being subjected to cor- 


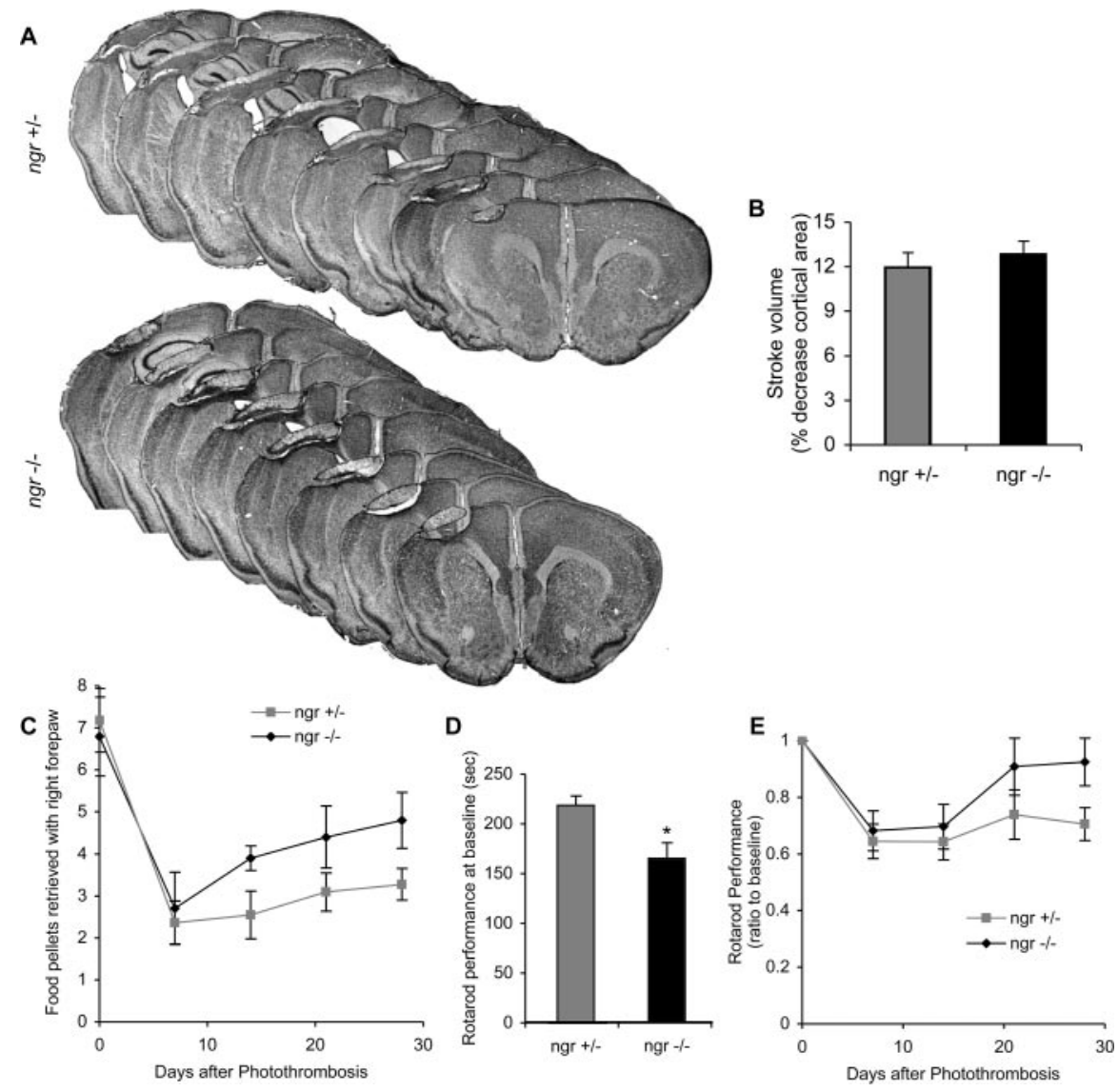

Figure 1. Behavioral recovery after stroke in $n g r-/-$ mice. $A, B$, Cresyl violet-stained coronal brain sections $28 \mathrm{~d}$ after photothrombosis. There is no difference in total infarct volume between $n g r+/-$ and $n g r-/-$ mice. C, Staircase test of skilled forelimb reaching ability. The photothrombotic lesion reduces the number of pellets retrieved with the contralateral forepaw. Significantly greater recovery during the postoperative period is observed in the $n g r-/-$ mice. ${ }^{* *} p<0.01$ (two-way parametric ANOVA). D, Rotarod performance at baseline is presented as the time spent on an accelerating rotarod at final pre-stroke training session. *Significantly different from $n g r+/-; p<0.05$ (Student's $t$ test). $E$, Rotoarod performance is expressed as a ratio to baseline (pre-lesion) performance at various times after stroke in mice of the indicated genotypes. Performance was significantly better in $n g r-/-$ mice after stroke. ${ }^{*} p<0.05$ (two-way parametric ANOVA). Data are mean \pm SEM from different animals. $n=10$ mice for $n g r+/-$ and $n=11$ mice for $n g r-/-$ in $B-E$.

tical ischemia to establish the baseline performance, and animals that did not learn to retrieve four pellets from each side during the last training session were excluded from the stroke surgery.

Histology and analysis. Two weeks after BDA injection, animals were perfused transcardially with PBS, followed by $4 \%$ paraformaldehydePBS solution. Brain and cervical spinal cord were dissected, postfixed overnight, and embedded in tissue-freezing medium for cryostat sectioning. The coronal sections from the brain and transverse sections from the spinal cord were incubated with avidin-biotin-peroxidase complex, and the BDA tracer was visualized by nickel-enhanced diaminobenzidine HRP reaction (GrandPre et al., 2002; Kim et al., 2003; Li and Strittmatter, 2003). The sections were mounted, dehydrated, and coverslipped with mounting medium. Images of each sections at red nucleus level were captured with a $10 \times$ objective lens. BDA-stained fiber lengths in one $0.85 \times 0.68 \mathrm{~mm}$ area centered on the red nucleus were traced with an image analysis system (Scion Image). For fiber counts at the level of the cervical enlargement of spinal cord, sections were examined with a $40 \times$ objective lens. BDA-positive fibers in the gray matter of one section on the side ipsilateral to the BDA injection were counted. One transverse section from each mouse was scored for all BDA-labeled fibers meeting these criteria.

Quantification of stroke volume. Eight coronal sections spaced at 0.5 $\mathrm{mm}$ intervals for the rats and $0.4 \mathrm{~mm}$ intervals for the mice throughout the forebrain of each animal were stained with cresyl violet acetate (Sigma) for determination of infarction size. The infarcted area was fully bracketed by this set of sections. Images of each section were digitized, and the infarct area per section was measured with image analysis software (Scion Image). The area of intact tissue in the left hemisphere was subtracted from the area of the contralateral hemisphere. Volume was interpolated across the eight sections. For mice, only cerebral cortical area was included in the measurements, because all strokes were superficial.

\section{Results \\ Stroke recovery is improved in mice lacking NgR}

Given that pharmacologic or genetic disruption of $\mathrm{NgR}$ function improves locomotor recovery after spinal cord injury, we investigated the role of the protein after stroke. Mice with a targeted mutation of the $n g r$ gene lack immunoreactive $\mathrm{NgR}$ protein (our unpublished observations). We compared the response of these mice versus heterozygous littermate control mice with a photothrombotic lesion of the left sensorimotor cortex. In this experiment, Rose Bengal is injected systemically, and then the cortex is illuminated at one focus to produce a discrete stroke based on light absorption by the dye (Boquillon et al., 1992; Schroeter et al., 2002). Lesion volumes at 1 month after injury are identical in $n g r+/-$ and $n g r-/-$ mice (Fig. $1 A, B)$.

Limb movement and open field locomotion return to normal very quickly after these cortical lesions in mice; however, persistent deficits in motor performance are detectable in control mice using two, more complicated tasks. In one test, foodrestricted mice are trained to retrieve food pellets from a staircase that positions the pellets at increasing distances from the body and allowed only the lesion-affected forepaw access to one set of pellets (Montoya et al., 1991; Virley et al., 2000; Baird et al., 2001). The number of pellets retrieved in this $30 \mathrm{~min}$ test of skilled limb movement drops from 7 to 2 in control mice and recovers slowly to 3-3.5 pellets per session over 1 month (Fig. $1 C)$. In the $n g r-/-$ mice, pellet retrieval after injury also drops to 2 after injury but recovers to a significantly $[p<0.01$; multivariate ANOVA (MANOVA)] greater level of 4.5 by 1 month. Motor behavior was also tested on the rotarod (Hunter et al., 2000; $\mathrm{Li}$ and Stephenson, 2002) (Fig. 1D,E). Ngr - /- mice perform less well on this test than do control mice at baseline, before the photothrombotic stroke (Fig. 1D); however, they recover to prestroke levels over 1 month, whereas the control heterozygous mice do not (Fig. $1 E$ ). After stroke, the $n g r-/-$ mice are indistinguishable on the rotarod test from control mice. Recovery as a percentage of baseline value is significantly $(p<0.05$; MANOVA) greater in the $n g r-/-$ mice.

After spinal cord injury, improved function in animals with disrupted NgR function is associated with axonal sprouting. We searched for evidence of increased plasticity after stroke in the $n g r$ $-/-$ mice. The axonal tracer BDA was injected into the intact (non-stroke) motor cortex, and then fibers were traced into the 

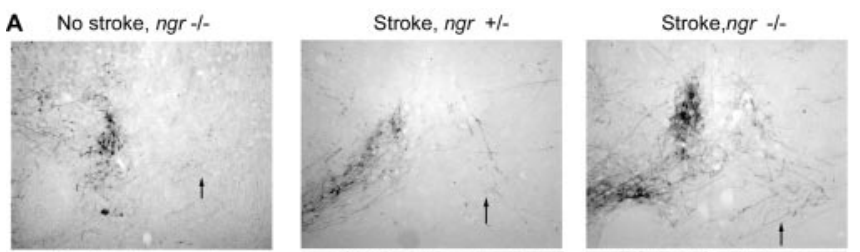

No Stroke, $n g r+1$
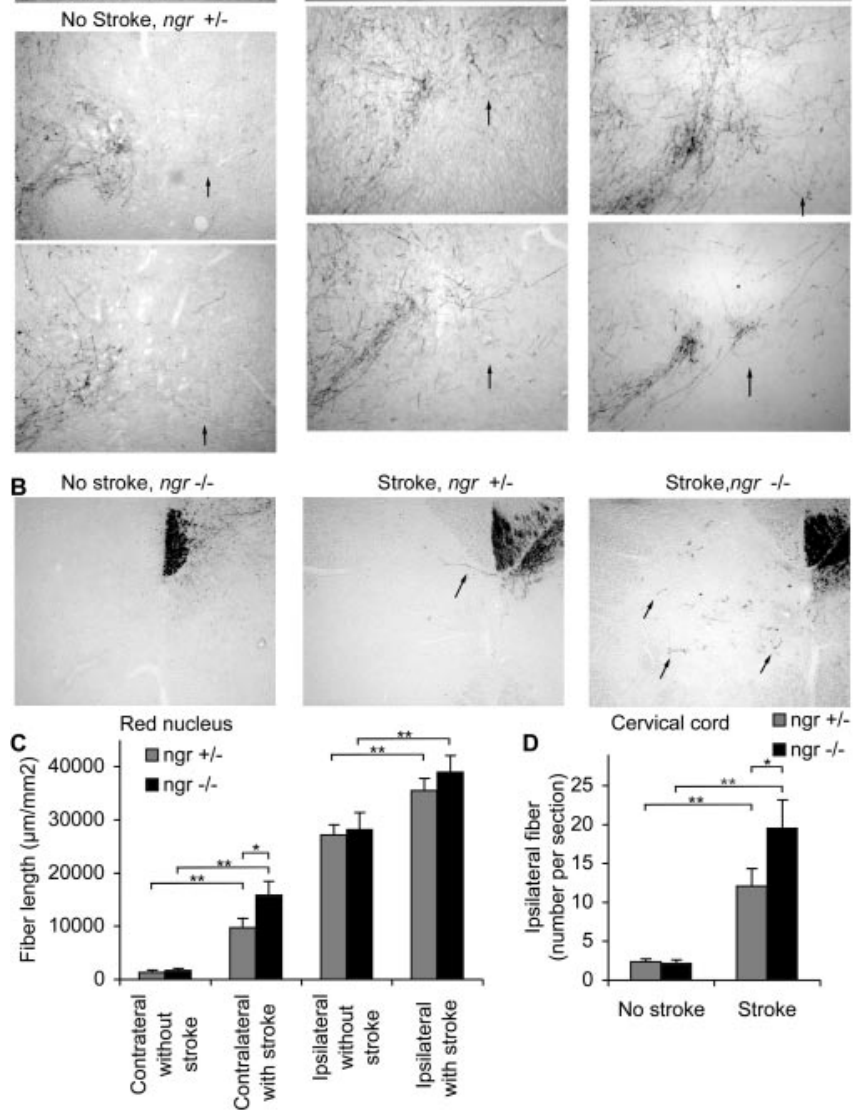

Figure 2. Corticofugal axonal plasticity after stroke in ngr - $/-$ mice. $A, B, B D A$-labeled axons traced from the uninjured cerebral cortex are illustrated in coronal sections at the level of the red nucleus $(A)$ and transverse sections of cervical spinal cord $(B)$ from different mice. Both $n g r+/-$ and $n g r-/-$ mice without stroke possess very few BDA-labeled fibers in the red nucleus contralateral to the tracer injection (arrow) or in the spinal gray matter ipsilateral to the injection (arrows). After stroke, the number of such fibers increases to a greater extent in the $n g r$ $-/-$ mice. Dorsal is up and the lesioned side is to the right in this and all micrographs. C, The total BDA-positive axon length per area of a coronal section centered on the red nucleus is plotted as a function of the side, genotype, and stroke. $D$, The total number of BDA-positive axons in the gray matter ipsilateral to the injection site per transverse section of the cervical spinal cord is plotted for the indicated conditions. Data are mean $\pm S E M$ from different animals. $n=10$ mice for $n g r+/-$ and $n=11$ mice for $n g r-/-$ in $C, D .{ }^{*} p<0.05$; ${ }^{* *} p<0.01$ (Student's $t$ test).

midbrain at the level of the red nucleus (Fig. 2A,C). Before a stroke, the pattern of labeling in $n g r-/-$ and control mice is identical, with a predominance of innervation confined to the side ipsilateral to the cortical injection. At 1 month after stroke, there is significantly more corticofugal fiber length observed in the contralateral midbrain; this reflects a level of endogenous axonal plasticity that is likely to contribute to motor recovery. In the $n g r-/-$ mice, this stroke-induced plasticity is doubled in comparison with control mice. The absence of $\mathrm{NgR}$ allows a greater number of corticorubral fibers from the intact hemisphere to sprout into the red nucleus denervated by the stroke. In fact, the contralateral innervation in $n g r-/-$ mice reaches a level $50 \%$ of that found in the ipsilateral red nucleus of uninjured animals. Ipsilateral innervation is increased slightly in response to stroke, and there is no significant difference in the absence of NgR.

Corticofugal fiber sprouting was also examined at a more caudal level, in the cervical enlargement of the spinal cord (Fig. $2 B, D)$. At this level, most of the corticofugal axons from the uninjured right cortex have crossed to the left side of the spinal cord and have formed a tight bundle as the dorsal corticospinal tract (CST). Without injury, only two or three CST fibers are observed in the gray matter on the right side of the spinal cord serving the affected limb. Stroke greatly increases the number of such fibers that are observed ipsilateral to the injection site to a count of 13 per section. The stroke-induced plasticity at the level of the cervical spinal cord is significantly greater in the $n g r-/-$ mice. Thus, enhanced axonal plasticity (and not altered stroke volume) is likely to account for the improved recovery of function after stroke in mice without a functional $\mathrm{NgR}$.

\section{Mice lacking Nogo-AB exhibit enhanced stroke recovery}

Mice deficient in Nogo-AB (Kim et al., 2003) were studied in the same photothrombotic stroke model with the same outcome measures. The sizes of photothrombotic lesions are slightly smaller in the nogo- $a b-/-$ mice than in control mice $(9 \%$ of cortical volume vs $11 \%$ of cortical volume), but this difference does not reach statistical significance (Fig. $3 A, B$ ).

In behavioral tests, the recovery of food pellet retrieval by the nogo- $a b-1-$ mice is significantly greater than in the heterozygous controls (Fig. 3C). Of note, a proportion of this improved functional recovery occurs early after stroke, in the period $2-7 \mathrm{~d}$ after injury. Similarly, the nogo- $a b-/-$ mice exhibit increased recovery of motor performance after stroke on the rotarod test of coordination (Fig. 3D). In part, the behavioral improvements may reflect a slightly reduced stroke volume, although the magnitude of the improvement makes it unlikely to be attributable solely to such a mechanism.

We examined axonal plasticity of the intact corticofugal system in these animals. Anterograde tracing with BDA demonstrated descending projections from the intact cortex. At the level of the red nucleus, the stroke induces a significant increase in fiber length on the side contralateral to the tracer injection (ipsilateral to the stroke) (Fig. 4A,C). This stroke-induced plasticity is enhanced in the nogo- $a b-/-$ mice. Increased corticofugal plasticity in the territory affected by the stroke is also observed in the cervical cord, and the enhancement of this sprouting is robust in the absence of Nogo-AB (Fig. $4 B, D$ ). Thus, the natural increase in axonal connections from the undamaged motor cortex to motor centers previously innervated by the stroke-damaged cortex is augmented by the loss of Nogo-AB.

\section{Delayed pharmacologic blockade of $\mathrm{NgR}$ promotes recovery from MCAO}

Because the genetic perturbation of Nogo-NgR function improved stroke recovery, we blocked NgR pharmacologically in a rat stroke model. In this case, the soluble $\mathrm{NgR}(310)$ Ecto-Fc protein was infused into the lateral ventricle of the rat on the side opposite the stroke. The continuous infusion was initiated $7 \mathrm{~d}$ after the stroke and continued for 2 months. Control animals received rat IgG at the same dose. Strokes were induced in these rats before protein infusion by permanent occlusion of the left middle cerebral artery with an intraluminal filament. Histological examination at 11 weeks after MCAO demonstrates reproducible stroke lesions and no significant difference in the size of the stroke between the $\mathrm{NgR}(310)$ Ecto-Fc protein-treated group 


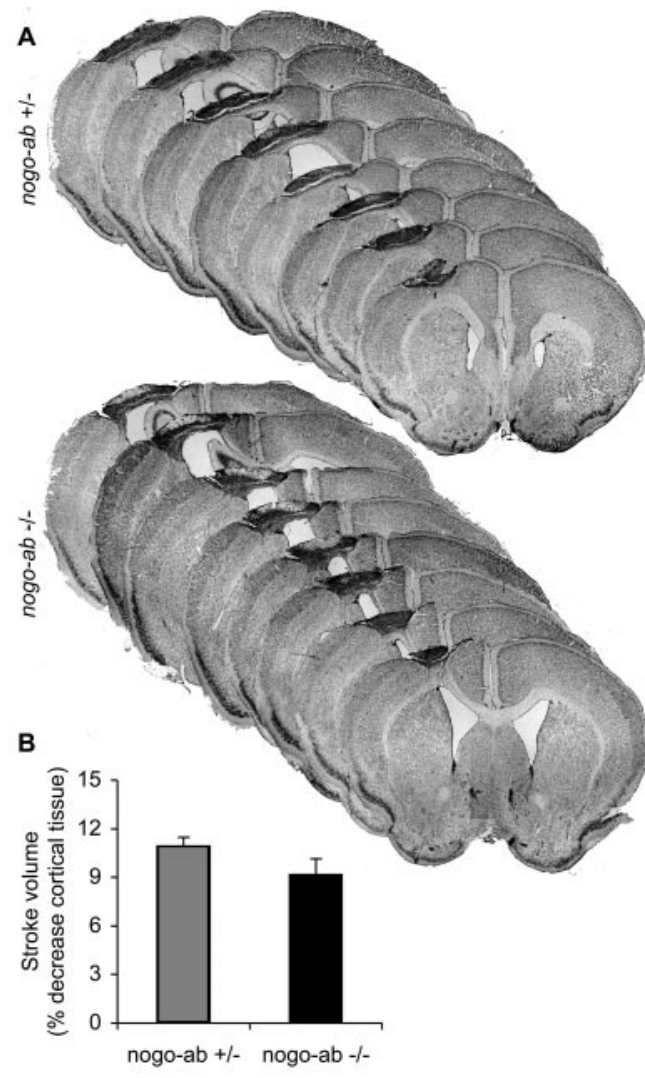

C
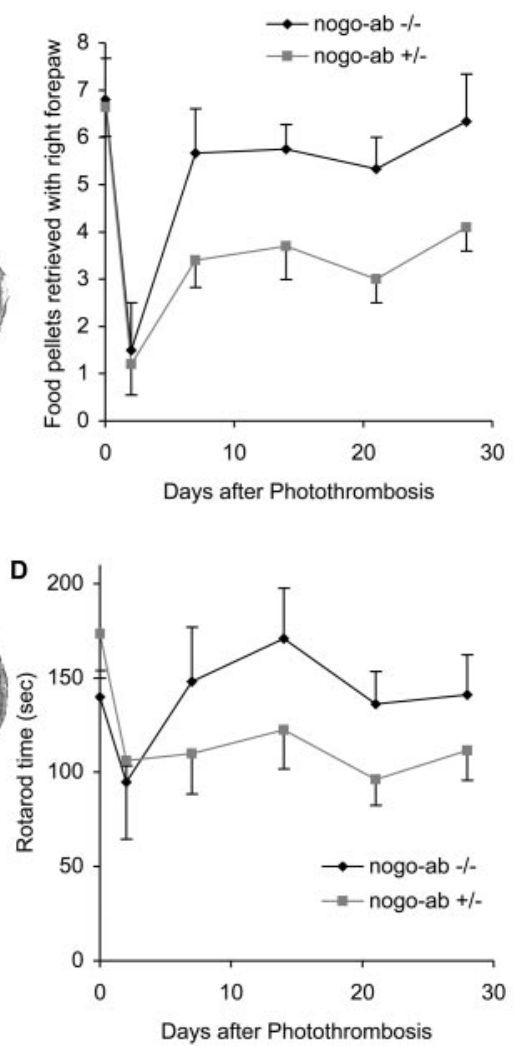

Figure 3. Recovery from cortical photothrombosis in mice lacking Nogo-AB. $A, B$, Cresyl violet-stained coronal brain sections $28 \mathrm{~d}$ after photothrombosis. Total infarct volume in nogo- $a b-/-$ mice is smaller than nogo- $a b+/-$ mice, although the difference is not significant at the $p<0.05$ level. $C, D$, Staircase test and rotarod test performance after stroke. Performance across the postoperative period is significantly improved in nogo- $a b-/-$ mice relative to the nogo-ab $+/-$ mice. ${ }^{* * *} p<0.001$ (two-way parametric ANOVA). Data are mean \pm SEM from different animals. $n=10$ mice for nogo- $a b+/-$ and $n=9$ nogo- $a b$ $-/-$ mice in $B-D$.

and the control group (Fig. 5A,B). Thus, any improvement in behavioral recovery after this treatment cannot be attributed to neuroprotection.

Behavioral recovery was assessed by the same tests used in the $n g r-/-$ and nogo- $a b-/-$ mice: the forepaw pellet retrieval task and the rotarod test (Fig. 6). In control rats, food pellet retrieval with the affected right forepaw drops from 8.5 per session in pre-stroke training to 1 per session at 1 week after stroke and slowly recovers to 4 pellets per session by 6 weeks after stroke. Recovery is significantly ( $p<0.001$; MANOVA) better and more rapid in the $\mathrm{NgR}(310)$ Ecto-Fc-treated group, achieving a level of six pellets per session by 4 weeks after stroke. A related parameter from the staircase test, the most distant step reached per session, shows a nearly identical pattern of greater improvement in the $\mathrm{NgR}(310)$ Ecto-Fc-treated group ( $p<0.001$; MANOVA; data not shown). Rotarod performance also improves to a significantly $(p<$ 0.01; MANOVA) greater extent in the $\mathrm{NgR}(310)$ Ecto-Fc-treated rats. In fact, no deficit is detectable at 9 weeks after stroke in the treated rats, whereas a persistent deficit is present in the control group.

Because the stroke volumes were identical in the $\mathrm{NgR}(310)$ EctoFc-treated rats but recovery was greater, we searched for evidence of increased axonal plasticity in the treated animals (Fig. 6). Evidence for sprouting of corticofugal fibers from the intact side to the stroke side was assessed at the level of the red nucleus with anterograde BDA tracing from the intact sensorimotor cortex. The pattern of corticofugal axonal plasticity in response to stroke is very similar to that seen in mice. There is a moderate increase of both ipsilateral and contralateral fiber sprouting in control IgG rats. Blockade of NgR function during the period from 1 to 9 weeks after MCAO results in significantly more contralateral fiber length at this level. The pattern of axons descending from the intact motor cortex to the ipsilateral cervical cord gray matter was also examined. Very few fibers are detectable in animals not subjected to MCAO. The stroke significantly increases the numbers of such fibers, and the $\operatorname{NgR}(310)$ Ecto-Fc protein treatment doubles this axonal plasticity response to stroke. As in both mouse strains, interruption of the Nogo-NgR pathway allows a greater degree of axonal plasticity in response to stroke, and this is associated with improved functional recovery of complicated motor tasks.

\section{Discussion}

We have used three independent methods to explore the role of the Nogo-NgR system in stroke recovery. Results from all three models, photothrombosis in ngr $-/-$ mice, photothrombosis in nogo- $a b$ - /- mice, and MCAO in NgR(310)EctoFc-treated rats, are quite similar. In each case, reduced Nogo-NgR function improves motor task performance, in some cases to pre-stroke levels. In all animals suffering a stroke, the axonal pathway emanating from the uninjured cerebral cortex undergoes significant sprouting from the intact side to the stroke-denervated side in the midbrain and the cervical spinal cord. This sprouting is enhanced by each of the three reductions in Nogo-NgR function. Taken together, these data demonstrate that reduction of $\mathrm{NgR}$ function after stroke allows increased anatomical plasticity and improved motor performance. This is not attributable to tissue preservation or protection. NgR antagonism provides a means to promote stroke recovery in the subacute period after injury.

In these studies, we assessed fibers emanating from the uninjured motor cortex and focused on two sites of descending projections: the red nucleus in the midbrain and the cervical enlargement of the spinal cord. Both of these sites are innervated in a predominantly unilateral pattern in uninjured rodents. After stroke in control animals, significant bilateral innervation occurs through the sprouting of uninjured corticofugal axons. In contrast, after spinal cord injury in control animals, no long distance growth of cut CST fibers occurs. Clearly, there is a greater propensity for short-range axonal sprouting from uninjured fibers than long-distance regeneration of injured fibers. This natural plasticity of uninjured corticofugal fibers adjacent to denervated areas may underlie at least a portion of stroke recovery. The increased bilaterality of corticofugal projections to the red nucleus and the spinal cord is unlikely to be the only axonal plasticity responsible for improved function. Further studies may reveal additional pathways adaptively regulated by stroke injury. The effect of Nogo-NgR antagonism is not to create new or different 


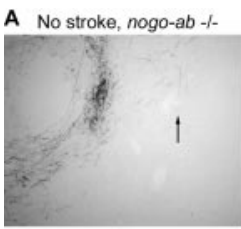

B No stroke, nogo-ab - -
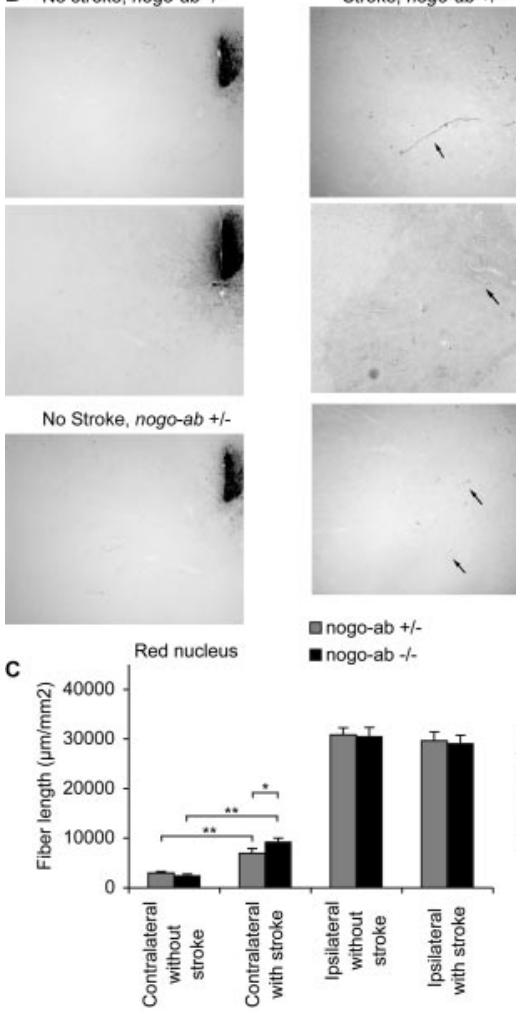

No Stroke, nogo-ab +1-
Stroke, nogo-ab $+1-$

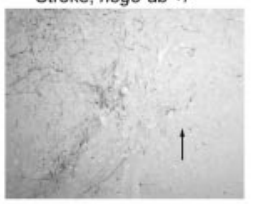

Stroke, nogo-ab+1-
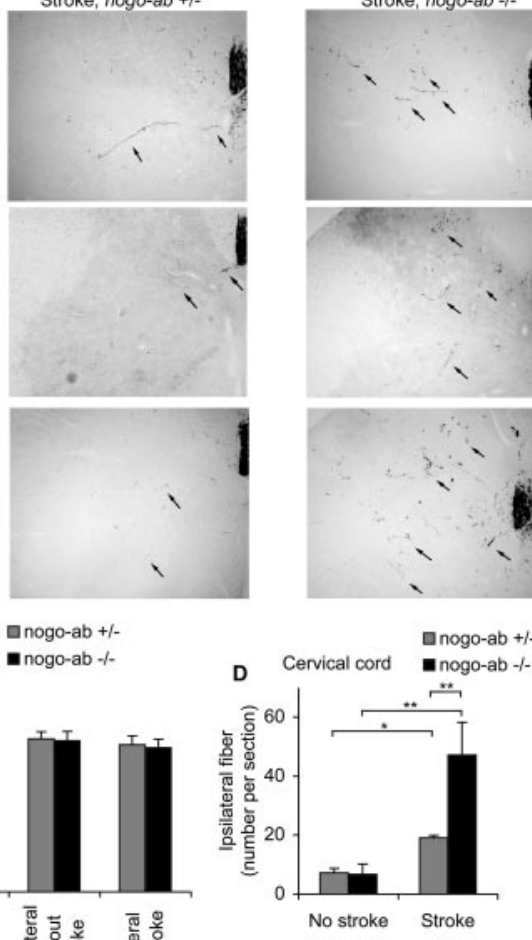

Figure 4. Corticofugal axonal plasticity after stroke in mice lacking Nogo-AB. $A, B, B D A-$ labeled axons traced from the uninjured cerebral cortex are illustrated at the level of the red nucleus $(A)$ and cervical spinal cord $(B)$ from different mice. In non-stroke mice there are few BDA-labeled fibers in the red nucleus contralateral to the tracer injection (arrow) or in the spinal gray matter ipsilateral to the injection (arrows), regardless of genotype. After stroke, the number of fibers sprouting into these areas increases to a higher level in the nogo- $a b-/-$ mice. $C$, The total BDA-positive axon length per area of a coronal section centered on the red nucleus is plotted as a function of the side, genotype, and stroke. D, The total number of BDA-positive axons in the gray matter ipsilateral to the injection site per transverse section of the cervical spinal cord is plotted for the indicated conditions. Data are mean \pm SEM from different animals. $n=10$ mice for nogo- $a b+/-$ and $n=9$ nogo- $a b-/-$ mice in $C, D .{ }^{*} p<0.05 ;{ }^{* *} p<0.01$ (Student's $t$ test).

pathways but is to significantly enhance endogenous anatomical plasticity. This implies that myelin-based inhibition of axonal sprouting plays a role in limiting axonal plasticity in response to the stroke injury. These data do not define a signal or mechanism by which the neurons in the uninjured cortex respond to ischemic damage in the contralateral cortex to initiate a sprouting response. One potential signal might be asymmetric electrical activity or synaptic occupancy in the midbrain or spinal cord. Alternatively, cortico-cortico connections may monitor activity in the contralateral injured hemisphere directly.

It is likely that $\mathrm{NgR}(310)$ Ecto-Fc acts as a decoy receptor to block myelin inhibitor action in vivo, as was demonstrated in vitro (Fournier et al., 2002). The NgR fusion protein binding to myelin inhibitors does not incite an experimental allergic encephalitis-like loss of function, and histologic examination of NgR(310)Ecto-Fctreated brain reveals no increased inflammation and no white matter

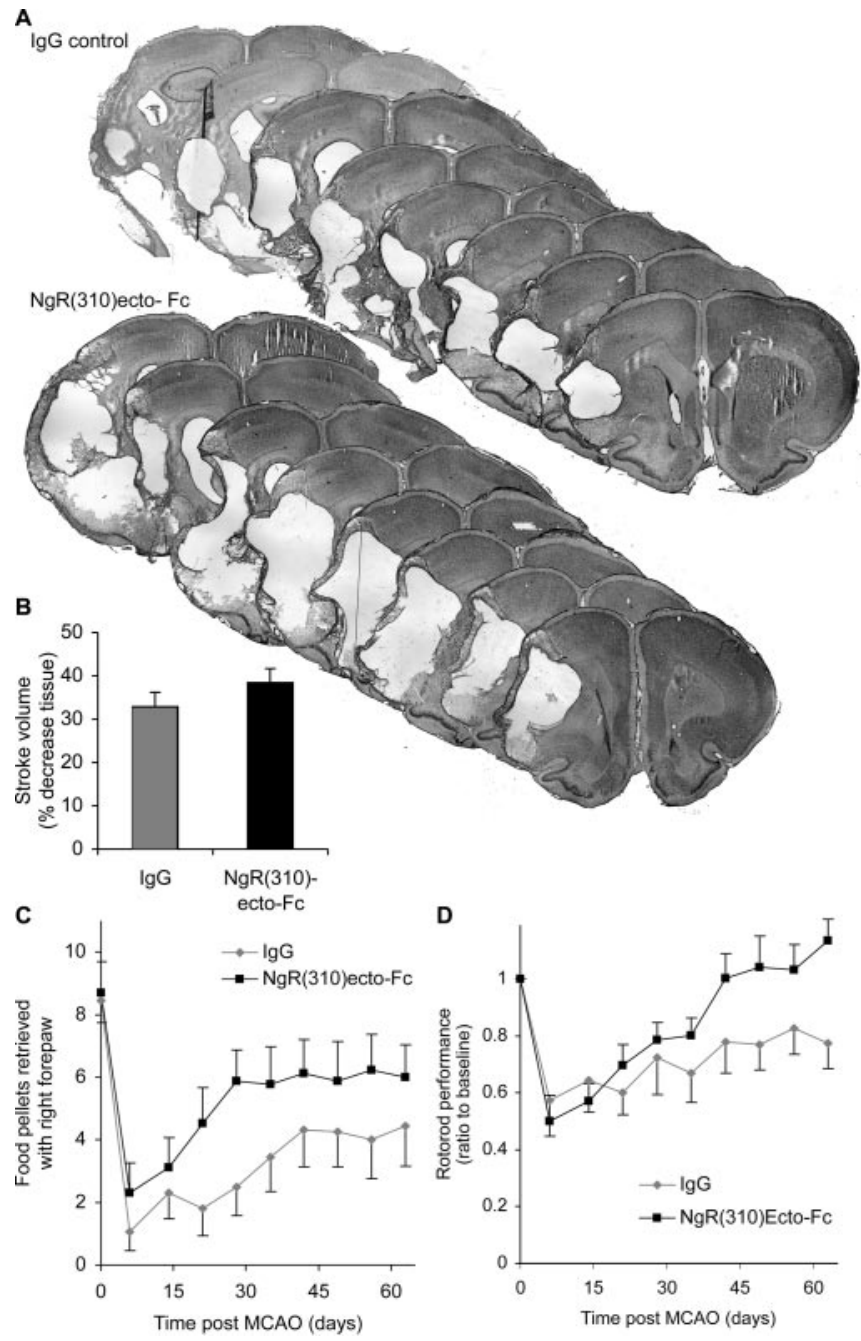

Figure 5. $\mathrm{NgR}(310) \mathrm{Ect0}-\mathrm{Fc}$ treatment of rats with MCAO stroke. $A$, Cresyl violet-stained sections of rat brain $77 \mathrm{~d}$ after MCAO and after intracerebroventricular treatment from day 7 to 63 with either $\lg G$ or $\mathrm{NgR}(310) E c t 0-F c$. B, Stroke volume. There is no significant effect of $\mathrm{NgR}(310)$ Ecto-Fc on infarct volume. C, Staircase test. The number of pellets retrieved with the contralateral forepaw is significantly increased in the $\mathrm{NgR}(310)$ Ecto-Fc group compared with the control group. ${ }^{* * *} p<0.001$ (two-way parametric ANOVA). D, Rotarod test. Postoperative performance ratio to baseline was significantly better in rats treated with $\mathrm{NgR}(310)$ Ecto-Fc. ${ }^{* *} p<0.01$ (two-way parametric ANOVA). Data are mean \pm SEM from different animals. $n=$ 16 rats for $\lg G$ and $n=17$ rats for $\mathrm{NgR}(310)$ Ecto-Fc in $B-D$.

loss (data not shown). The behavioral and anatomical results obtained here with Nogo-NgR perturbation are similar to, but of greater magnitude than, those observed with anti-Nogo-A antibodies (Papadopoulos et al., 2002; Wiessner et al., 2003). These antibodies target an independent activity of the amino-Nogo domain of Nogo-A, but they may impinge allosterically on Nogo-66 signaling (Fournier et al., 2001; Wiessner et al., 2003). To the extent that antiNogo-A antibodies act on a domain of Nogo-A that signals through a different receptor mechanism, blockade of this domain and NgR may function synergistically. Specifically, a combination $\mathrm{NgR}(310)$ Ecto-Fc and anti-Nogo-A antibodies may produce greater effects than either reagent alone. The corticorubral sprouting and improved forelimb reaching observed here is also quite similar to that obtained by immediate infusion of inosine after stroke (Chen et al., 2002). Because the inosine effects are thought to be independent of the Nogo-NgR pathway, it is plausible that $\mathrm{NgR}(310)$ Ecto-Fc and inosine treatments would be synergistic in promoting greater axonal plasticity and stroke recovery. 

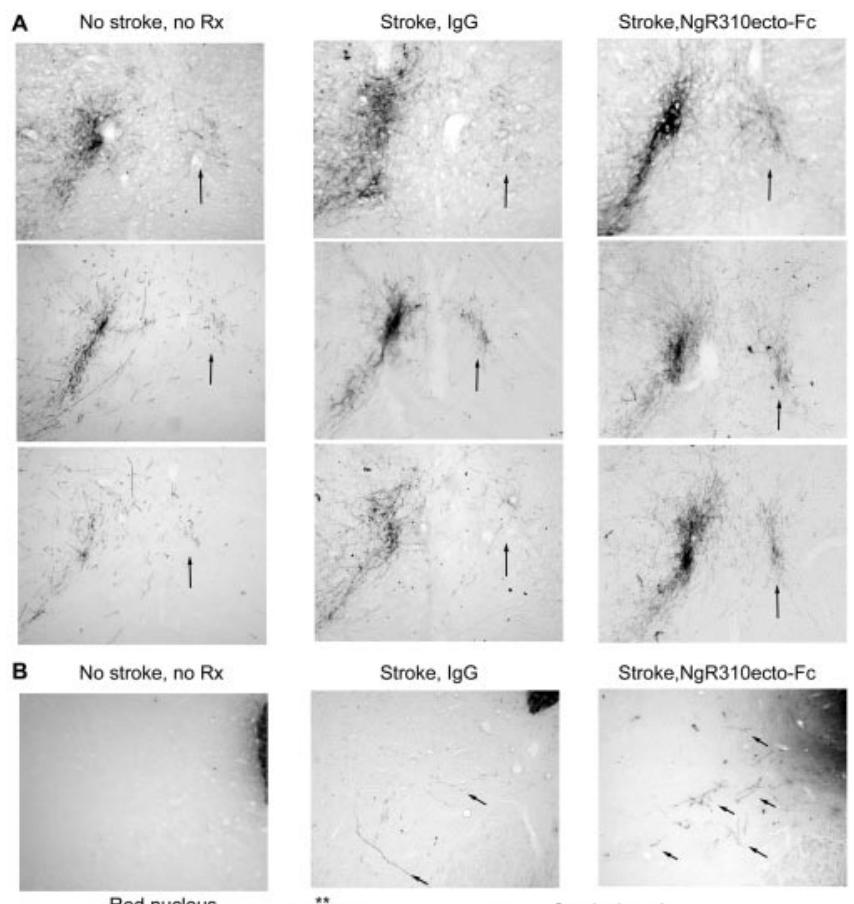

Stroke, IgG
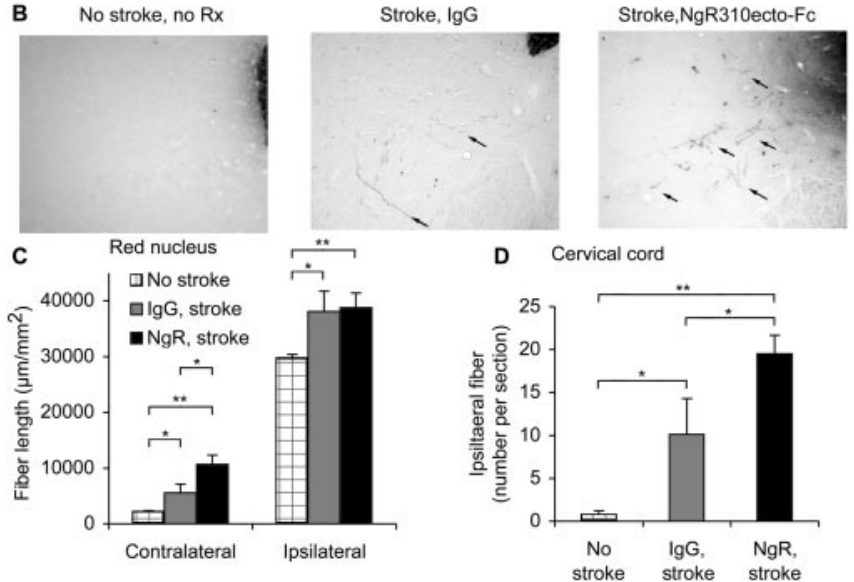

Figure 6. Corticofugal axonal plasticity after MCAO in rats treated with $\mathrm{NgR}(310) \mathrm{Ect0}-\mathrm{Fc} . \mathrm{A}$, $B, \mathrm{BDA}$-labeled axons traced from the uninjured cerebral cortex are illustrated at the level of the red nucleus $(A)$ and cervical spinal cord $(B)$ from different rats. Control rats with no stroke and no treatment exhibit very few BDA-labeled fibers in the red nucleus contralateral to the tracer injection (arrow) or in the spinal gray matter ipsilateral to the injection (arrows). After stroke, many BDA-labeled fibers sprouting into the territory normally innervated by the infracted cortex are present. This is more prominent in rats treated with $\mathrm{NgR}(310)$ Ecto-Fc than in control lgG rats. $C$, The total BDA-positive axon length per area of a coronal section centered on the red nucleus is plotted as a function of the side, protein infusion, and stroke. $D$, The total number of BDA-positive axons in the gray matter ipsilateral to the injection site per transverse section of the cervical spinal cord is plotted for the indicated conditions. Data are mean \pm SEM from different animals. $n=16$ rats for $\lg$ and $n=17$ rats for $\mathrm{NgR}(310)$ Ecto-Fc in $C, D .{ }^{*} p<0.05$; ${ }^{* *} p<0.01$ (Student's $t$ test).

The nogo- $a b-/-$ mice respond to stroke in a subtly different manner than do $n g r-/-$ mice or the $\mathrm{NgR}(310)$ Ecto-Fc-treated rats. Although the enhanced axonal plasticity effect is identical, there is a slight (but nonsignificant) reduction in stroke volume and a more rapid improvement in behavioral recovery. Recently, we found that vascular expression of Nogo-B plays a role in limiting vascular remodeling independent from $\mathrm{NgR}$ (Acevedo et al., 2004). One possible explanation for the minor differences in the nogo- $a b-/-$ mice is related to the loss of Nogo-B expression from endothelial and vascular smooth muscle cells. The absence of Nogo-B may allow enhanced vascular remodeling and rescue a small amount of peri-infarct cerebral cortical tissue. Reduced stroke damage would provide a secondary mechanism to explain the early phase of functional recovery. Regardless of potential slight contributions of vascular Nogo-B, that axonal plasticity is clearly enhanced several weeks after stroke in animals lacking Nogo-AB.
The current $\operatorname{NgR}(310)$ Ecto-Fc treatment protocol delivered the protein intracerebroventricularly. A similar approach may prove technically difficult in some cases of clinical stroke; however, there are indications that NgR antagonism might be delivered systemically to the injured CNS. After spinal cord injury, the blood-brain barrier is broken down for several weeks after injury, and subcutaneous administration of the $\mathrm{NgR}$ antagonist peptide, NEP1-40, is effective in enhancing axonal growth and improving locomotion after SCI (Li and Strittmatter, 2003). Similarly, after stroke, the blood-brain barrier is disrupted for several weeks, and this provides the potential for access to the CNS. Alternatively, the recent determination of the NgR structure (Barton et al., 2003; He et al., 2003) may lead to the identification of small molecule $\mathrm{NgR}$ antagonists with CNS access to promote stroke recovery.

Current pharmacological stroke therapy focuses on preventive strategies to reduce risk and on immediate acute thrombolytic and neuroprotective strategies to reduce damage to the brain. The potential for enhancing recovery from subacute stroke provides a new modality for pharmaceutical intervention; this potential is currently addressed in the clinic only by physical therapy. Clearly there is a significant degree of stroke-induced plasticity of axonal connectivity without treatment, but interruption of the Nogo-NgR pathway enhances this adaptive recovery mechanism.

\section{References}

Acevedo L, Yu J, Erdjument-Bromage H, Qing Miao R, Kim J-E, Fulton D, Tempst P, Strittmatter SM, Sessa WC (2004) A novel role for Nogo as a regulator of vascular remodeling. Nat Med 10:382-388.

Baird AL, Meldrum A, Dunnett SB (2001) The staircase test of skilled reaching in mice. Brain Res Bull 54:243-250.

Barton WA, Liu BP, Tzvetkova D, Jeffrey PD, Fournier AE, Sah D, Cate R, Strittmatter SM, Nikolov DB (2003) Structure and axon outgrowth inhibitor binding of the Nogo-66 receptor and related proteins. EMBO J 22:3291-3302.

Bartsch U, Bandtlow CE, Schnell L, Bartsch S, Spillmann AA, Rubin BP, Hillenbrand R, Montag D, Schwab ME, Schachner M (1995) Lack of evidence that myelin-associated glycoprotein is a major inhibitor of axonal regeneration in the CNS. Neuron 15:1375-1381.

Belayev L, Alonso OF, Busto R, Zhao W, Ginsberg MD (1996) Middle cerebral artery occlusion in the rat by intraluminal suture. Neurological and pathological evaluation of an improved model. Stroke 27:1616-1622.

Bland ST, Pillai RN, Aronowski J, Grotta JC, Schallert T (2001) Early overuse and disuse of the affected forelimb after moderately severe intraluminal suture occlusion of the middle cerebral artery in rats. Behav Brain Res 126:33-41.

Bonita R, Beaglehole R (1988) Recovery of motor function after stroke. Stroke 19:1497-1500.

Boquillon M, Boquillon JP, Bralet J (1992) Photochemically induced, graded cerebral infarction in the mouse by laser irradiation evolution of brain edema. J Pharmacol Toxicol Methods 27:1-6.

Bregman BS, Kunkel-Bagden E, Schnell L, Dai HN, Gao D, Schwab ME (1995) Recovery from spinal cord injury mediated by antibodies to neurite growth inhibitors. Nature 378:498-501.

Brosamle C, Huber AB, Fiedler M, Skerra A, Schwab ME (2000) Regeneration of lesioned corticospinal tract fibers in the adult rat induced by a recombinant, humanized IN-1 antibody fragment. J Neurosci 20:8061-8068.

Chen MS, Huber AB, van der Haar ME, Frank M, Schnell L, Spillmann AA, Christ F, Schwab ME (2000) Nogo-A is a myelin-associated neurite outgrowth inhibitor and an antigen for monoclonal antibody IN-1. Nature 403:434-439.

Chen P, Goldberg DE, Kolb B, Lanser M, Benowitz LI (2002) Inosine induces axonal rewiring and improves behavioral outcome after stroke. Proc Natl Acad Sci USA 99:9031-9036. 
Dijkhuizen RM, Ren J, Mandeville JB, Wu O, Ozdag FM, Moskowitz MA, Rosen BR, Finklestein SP (2001) Functional magnetic resonance imaging of reorganization in rat brain after stroke. Proc Natl Acad Sci USA 98:12766-12771.

Domeniconi M, Cao Z, Spencer T, Sivasankaran R, Wang K, Nikulina E, Kimura N, Cai H, Deng K, Gao Y, He Z, Filbin M (2002) Myelinassociated glycoprotein interacts with the Nogo66 receptor to inhibit neurite outgrowth. Neuron 35:283-290.

Feydy A, Carlier R, Roby-Brami A, Bussel B, Cazalis F, Pierot L, Burnod Y, Maier MA (2002) Longitudinal study of motor recovery after stroke: recruitment and focusing of brain activation. Stroke 33:1610-1617.

Foltys H, Krings T, Meister IG, Sparing R, Boroojerdi B, Thron A, Topper R (2003) Motor representation in patients rapidly recovering after stroke: a functional magnetic resonance imaging and transcranial magnetic stimulation study. Clin Neurophysiol 114:2404-2415.

Fournier AE, GrandPre T, Strittmatter SM (2001) Identification of a receptor mediating Nogo-66 inhibition of axonal regeneration. Nature 409:341-346.

Fournier AE, Gould GC, Liu BP, Strittmatter SM (2002) Truncated soluble Nogo receptor binds Nogo-66 and blocks inhibition of axon growth by myelin. J Neurosci 22:8876-8883.

Fujii Y, Nakada T (2003) Cortical reorganization in patients with subcortical hemiparesis: neural mechanisms of functional recovery and prognostic implication. J Neurosurg 98:64-73.

GrandPre T, Nakamura F, Vartanian T, Strittmatter SM (2000) Identification of the Nogo inhibitor of axon regeneration as a Reticulon protein. Nature 403:439-444.

GrandPre T, Li S, Strittmatter SM (2002) Nogo-66 receptor antagonist peptide promotes axonal regeneration. Nature 417:547-551.

Harrigan MR, Ennis SR, Masada T, Keep RF (2002) Intraventricular infusion of vascular endothelial growth factor promotes cerebral angiogenesis with minimal brain edema. Neurosurgery 50:589-598.

He XL, Bazan JFGM, Park JB, Wang K, Tessier-Lavigne M, He Z, Garcia KC (2003) Structure of the Nogo receptor ectodomain: a recognition module implicated in myelin inhibition. Neuron 38:177-185.

Huang DW, McKerracher L, Braun PE, David S (1999) A therapeutic vaccine approach to stimulate axon regeneration in the adult mammalian spinal cord. Neuron 24:639-647.

Hudzik TJ, Borrelli A, Bialobok P, Widzowski D, Sydserff S, Howell A, Gendron P, Corbett D, Miller J, Palmer GC (2000) Long-term functional end points following middle cerebral artery occlusion in the rat. Pharmacol Biochem Behav 65:553-562.

Hunter AJ, Hatcher J, Virley D, Nelson P, Irving E, Hadingham SJ, Parsons AA (2000) Functional assessments in mice and rats after focal stroke. Neuropharmacology 39:806-816.

Hurwitz BE, Dietrich WD, McCabe PM, Alonso O, Watson BD, Ginsberg MD, Schneiderman N (1991) Amphetamine promotes recovery from sensory-motor integration deficit after thrombotic infarction of the primary somatosensory rat cortex. Stroke 22:648-654.

Kawamata T, Dietrich WD, Schallert T, Gotts JE, Cocke RR, Benowitz LI, Finklestein SP (1997) Intracisternal basic fibroblast growth factor enhances functional recovery and up-regulates the expression of a molecular marker of neuronal sprouting following focal cerebral infarction. Proc Natl Acad Sci USA 94:8179-8184.

Kim JE, Li S, GrandPre T, Qiu D, Strittmatter SM (2003) Axon regeneration in young adult mice lacking Nogo-A/B. Neuron 38:187-199.

Knecht S, Imai T, Kamping S, Breitenstein C, Henningsen H, Lutkenhoner B, Ringelstein EB (2001) D-Amphetamine does not improve outcome of somatosensory training. Neurology 57:2248-2252.

Li Q, Stephenson D (2002) Postischemic administration of basic fibroblast growth factor improves sensorimotor function and reduces infarct size following permanent focal cerebral ischemia in the rat. Exp Neurol 177:531-537.

Li S, Strittmatter SM (2003) Delayed systemic Nogo-66 receptor antagonist promotes recovery from spinal cord injury. J Neurosci 23:4219-4227.

Liepert J, Uhde I, GrafS, Leidner O, Weiller C (2001) Motor cortex plasticity during forced-use therapy in stroke patients: a preliminary study. J Neurol 248:315-321.

Liu BP, Fournier A, GrandPre T, Strittmatter SM (2002) Myelin-associated glycoprotein as a functional ligand for the Nogo-66 receptor. Science 297:1190-1193.
Longa EZ, Weinstein PR, Carlson S, Cummins R (1989) Reversible middle cerebral artery occlusion without craniectomy in rats. Stroke 20:84-91.

McGee AW, Strittmatter SM (2003) The Nogo-66 receptor: focusing myelin inhibition of axon regeneration. Trends Neurosci 26:193-198.

McKerracher L, David S, Jackson DL, Kottis V, Dunn RJ, Braun PE (1994) Identification of myelin-associated glycoprotein as a major myelinderived inhibitor of neurite growth. Neuron 13:805-811.

Montoya CP, Campbell-Hope LJ, Pemberton KD, Dunnett SB (1991) The "staircase test": a measure of independent forelimb reaching and grasping abilities in rats. J Neurosci Methods 36:219-228.

Mukhopadhyay G, Doherty P, Walsh FS, Crocker PR, Filbin MT (1994) A novel role for myelin-associated glycoprotein as an inhibitor of axonal regeneration. Neuron 13:757-767.

Nakamura S, Murayama N, Noshita T, Annoura H, Ohno T (2001) Progressive brain dysfunction following intracerebroventricular infusion of beta(1-42)-amyloid peptide. Brain Res 912:128-136.

Papadopoulos CM, Tsai SY, Alsbiei T, O’Brien TE, Schwab ME, Kartje GL (2002) Functional recovery and neuroanatomical plasticity following middle cerebral artery occlusion and IN-1 antibody treatment in the adult rat. Ann Neurol 51:433-441.

Pineiro R, Pendlebury S, Johansen-Berg H, Matthews PM (2001) Functional MRI detects posterior shifts in primary sensorimotor cortex activation after stroke: evidence of local adaptive reorganization? Stroke 32:1134-1139.

Prinjha R, Moore SE, Vinson M, Blake S, Morrow R, Christie G, Michalovich D, Simmons DL, Walsh FS (2000) Inhibitor of neurite outgrowth in humans. Nature 403:383-384.

Reding MJ, Potes E (1988) Rehabilitation outcome following initial unilateral hemispheric stroke. Life table analysis approach. Stroke 19:1354-1358.

Schaechter JD, Kraft E, Hilliard TS, Dijkhuizen RM, Benner T, Finklestein SP, Rosen BR, Cramer SC (2002) Motor recovery and cortical reorganization after constraint-induced movement therapy in stroke patients: a preliminary study. Neurorehabil Neural Repair 16:326-338.

Schnell L, Schwab ME (1990) Axonal regeneration in the rat spinal cord produced by an antibody against myelin-associated neurite growth inhibitors. Nature 343:269-272.

Schroeter M, Jander S, Stoll G (2002) Non-invasive induction of focal cerebral ischemia in mice by photothrombosis of cortical microvessels: characterization of inflammatory responses. J Neurosci Methods 117:43-49.

Simonen M, Pedersen V, Weinmann O, Schnell L, Buss A, Ledermann B, Christ F, Sansig G, van der Putten H, Schwab ME (2003) Systemic deletion of the myelin-associated outgrowth inhibitor Nogo-A improves regenerative and plastic responses after spinal cord injury. Neuron 38:201-211.

Small SL, Hlustik P, Noll DC, Genovese C, Solodkin A (2002) Cerebellar hemispheric activation ipsilateral to the paretic hand correlates with functional recovery after stroke. Brain 125:1544-1557.

Sonde L, Nordstrom M, Nilsson CG, Lokk J, Viitanen M (2001) A doubleblind placebo-controlled study of the effects of amphetamine and physiotherapy after stroke. Cerebrovasc Dis 12:253-257.

Stroemer RP, Kent TA, Hulsebosch CE (1998) Enhanced neocortical neural sprouting, synaptogenesis, and behavioral recovery with D-amphetamine therapy after neocortical infarction in rats. Stroke 29:2381-2393.

van der Lee JH, Wagenaar RC, Lankhorst GJ, Vogelaar TW, Deville WL, Bouter LM (1999) Forced use of the upper extremity in chronic stroke patients: results from a single-blind randomized clinical trial. Stroke 30:2369-2375.

Virley D, Beech JS, Smart SC, Williams SC, Hodges H, Hunter AJ (2000) A temporal MRI assessment of neuropathology after transient middle cerebral artery occlusion in the rat: correlations with behavior. J Cereb Blood Flow Metab 20:563-582.

Wade DT, Hewer RL (1987) Functional abilities after stroke: measurement, natural history and prognosis. I Neurol Neurosurg Psychiatry 50:177-182.

Walker-Batson D, Smith P, Curtis S, Unwin H, Greenlee R (1995) Amphetamine paired with physical therapy accelerates motor recovery after stroke. Further evidence. Stroke 26:2254-2259. 
Walker-Batson D, Curtis S, Natarajan R, Ford J, Dronkers N, Salmeron E, Lai J, Unwin DH (2001) A double-blind, placebo-controlled study of the use of amphetamine in the treatment of aphasia. Stroke 32:2093-2098.

Wang KC, Koprivica V, Kim JA, Sivasankaran R, Guo Y, Neve RL, He Z (2002) Oligodendrocyte-myelin glycoprotein is a Nogo receptor ligand that inhibits neurite outgrowth. Nature 417:941-944.

Werhahn KJ, Conforto AB, Kadom N, Hallett M, Cohen LG (2003) Contribution of the ipsilateral motor cortex to recovery after chronic stroke. Ann Neurol 54:464-472.

Wiessner C, Bareyre FM, Allegrini PR, Mir AK, Frentzel S, Zurini M, Schnell L, Oertle T, Schwab ME (2003) Anti-Nogo-A antibody infusion 24 hours after experimental stroke improved behavioral outcome and corticospinal plasticity in normotensive and spontaneously hypertensive rats. J Cereb Blood Flow Metab 23:154-165.

Wolf SL, Blanton S, Baer H, Breshears J, Butler AJ (2002) Repetitive task practice: a critical review of constraint-induced movement therapy in stroke. Neurology 8:325-338.

Zemke AC, Heagerty PJ, Lee C, Cramer SC (2003) Motor cortex organization after stroke is related to side of stroke and level of recovery. Stroke 34:23-28.

Zheng B, Ho C, Li S, Keirstead H, Steward O, Tessier-Lavigne M (2003) Lack of enhanced spinal regeneration in Nogo-deficient mice. Neuron 38:213-224. 